This item was submitted to Loughborough's Research Repository by the author.

Items in Figshare are protected by copyright, with all rights reserved, unless otherwise indicated.

\title{
Porous electrospun polycaprolactone fibres: Effect of process parameters
}

PLEASE CITE THE PUBLISHED VERSION

http://dx.doi.org/10.1002/polb.24090

\section{PUBLISHER}

(c) Wiley

\section{VERSION}

AM (Accepted Manuscript)

\section{PUBLISHER STATEMENT}

This work is made available according to the conditions of the Creative Commons Attribution-NonCommercialNoDerivatives 4.0 International (CC BY-NC-ND 4.0) licence. Full details of this licence are available at: https://creativecommons.org/licenses/by-nc-nd/4.0/

\section{LICENCE}

CC BY-NC-ND 4.0

\section{REPOSITORY RECORD}

Katsogiannis, Konstantinos A.G., Goran T. Vladisavljevic, and Stella Georgiadou. 2016. "Porous Electrospun Polycaprolactone Fibres: Effect of Process Parameters". figshare. https://hdl.handle.net/2134/20765. 


\title{
Porous Electrospun Polycaprolactone Fibres: Effect of Process Parameters.
}

Konstantinos Alexandros G. Katsogiannis, Goran T. Vladisavljević, Stella Georgiadou

Department of Chemical Engineering, Loughborough University, Loughborough, Leicestershire, LE11 3TU, UK

\begin{abstract}
The effect of electrospinning process parameters (solution flow rate, applied voltage, spinning distance) on the size and surface morphology of porous electrospun poly( $\varepsilon$-caprolactone) was investigated in this study. Response surface methodology was implemented for the design and conduction of electrospinning experiments. The feed solution was a $12.5 \% \mathrm{w} / \mathrm{v}$ poly $(\varepsilon$-caprolactone) $(\mathrm{PCL})$ solution in a binary solvent mixture of $90 \% \mathrm{v} / \mathrm{v}$ chloroform/ dimethyl sulfoxide. Spinning distance of $10-25 \mathrm{~cm}$, applied voltage of $10-25 \mathrm{kV}$ and feed flow rate of $0.5-5 \mathrm{ml} / \mathrm{h}$ were the range of limiting values of the independent variables used for the development of a central composite design. Second order polynomial equations, correlating electrospinning process parameters to relative pore coverage and fibre average diameter were developed and validated. An increase in any of the electrospinning process parameters favoured pore formation and fibre diameter increase. Under the experimental conditions investigated, the relative pore surface coverage was $15.8-31.9 \%$ and the average fibre diameter was in the range of 1.6-3.3 $\mu \mathrm{m}$. Applied voltage was proven to be the parameter with the strongest impact on both, fibre diameter and surface morphology.
\end{abstract}

\section{Introduction}

Porous electrospun fibres have the potential to bring about significant advances in many applications such as energy, environmental and healthcare applications. The apparent advantage of porous fibres over those with smooth surface is the higher specific surface area, which makes them ideal candidates for filtration media, absorbents and catalyst supports. In the field of production of scaffolds for tissue engineering, porous surfaces have been proven to favour cell attachment ${ }^{1}$, and cell proliferation and spreading on the scaffold ${ }^{2}$. In addition to that, surface porosity increases the toughness of the fibres, since pores can absorb the applied on the fibre surface stress ${ }^{3}$.

The use of humidity and phase separation are two main methods that have been proposed for the single step pore generation on electrospun fibres. Humidity can generate porosity through breath figures mechanism ${ }^{4}$, where the solvent evaporation 
causes cooling down of the fibre surface. Water condensation takes place on the cooled surface, leaving an imprint on it. The evaporation of the liquid water from surface is the last step of that mechanism. An alternative mechanism through which humidity can contribute to pore formation is phase separation. Combinations of phase separation and electrospinning are among the most effective methods that have been proposed for the formation of pores on the surface of electrospun fibres. The key parameter in this process is the induction of thermodynamic instability in a polymer solution, which causes its separation to polymer rich and polymer poor phases. The polymer rich phase forms a matrix, on which the pores are formed from the polymer poor phase. The instability can be caused by the polymer, e.g. the use of amphiphilic block copolymers in a solution able to dissolve only one of the copolymers $^{5}$, the reduction of temperature ${ }^{6}$ and by the addition of a non-solvent, either during electrospinning ${ }^{7}$ (Vapour Induced Phase Separation) or prior to electrospinning 8 (Non-solvent Induced Phase Separation). The latter method holds the advantages of simplicity, in terms of equipment requirements, and flexibility, in terms of potential solution alterations.

The aim of this study was to investigate the effect of electrospinning process parameters (applied voltage, solution flow rate, tip to collector distance) on porous electrospun poly( $\varepsilon$-caprolactone) fibre size and surface morphology. Unlikely other pore generating mechanisms, such as breath figures mechanism ${ }^{9}$ and reactive electrospinning ${ }^{10}$, the effect of electrospinning process parameters on pore formation, via Non-solvent Induced Phase Separation, has not been extensively studied before. Qi et $\mathrm{al}^{8}$ investigated the effect of process parameter on electrospun Poly(L-lactic acid) fibres, but their study was limited only on the voltage. The correlation of the process parameter to the morphological characteristics of the produced fibres can provide the simplest and most convenient method for the fibre production optimization. A $12.5 \% \mathrm{w} / \mathrm{v} \mathrm{PCL}$ solution in 90\% v/v chloroform (CF)/ Dimethyl sulfoxide (DMSO) was proven to be suitable for the production of porous, bead free fibres $^{11}$. Response surface methodology (RSM) was employed in this study, due to the number of variables influencing the outcome of the experiment and their interactions $^{12}$. Figure 1 summarizes the basic steps of the process. 


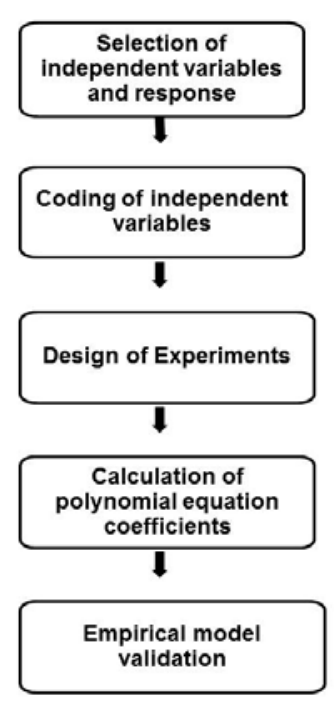

Figure 1. Basic Response Surface Methodology steps ${ }^{13}$.

After selection of the independent (applied voltage, solution flow rate, tip to collector distance) and the dependent variables (fibre average diameter, relative pore covered area) a design of experiments assisted in the determination of the minimum number of required experiments. The experimental data were fitted into second order polynomial equations correlating the independent to dependent variables. The equations were validated and analysed for the determination of individual parameter effects and the comparison of the effect between individual parameters on the responses.

\section{Experimental}

\subsection{Materials and electrospinning}

All the chemicals were purchased from Sigma - Aldrich and used as delivered. CF was ACS reagent, had purity $\geq 99.8 \%$ and contained ethanol as a stabilizer. DMSO was ACS reagent, had purity $\geq 99.9 \%$. PCL had an average number molecular weight of 80,000 . The electrospinning solution was prepared at room temperature. A horizontal electrospinning set up was used for the experiments. A syringe, loaded with $20 \mathrm{ml}$ of solution syringe was placed on a syringe pump (PHD ULTRA, Harvard Apparatus). A high voltage power supply (Series FC, Glassman High Voltage Inc) provided the current to the metallic needle (18 gauge, $1.270 \mathrm{~mm}$ outer diameter, $0.838 \mathrm{~mm}$ inner diameter, $3.2 \mathrm{~cm}$ length, Fisher Scientific). The fibres were collected on a flat copper plate covered with aluminium foil. All the electrospinning experiments were performed the same day under relative humidity levels of $\underline{40 \% \pm 5 \%}$ and temperature around $20^{\circ} \mathrm{C}$, within a closed chamber.

\subsection{Design of Experiments}


An initial screening was performed for the determination of a suitable range of values of the independent parameters for the experimental design. The range had to be as wide as possible, to allow the collection of sufficient amount of fibres and to lead to production of porous, bead free fibres. The range that was used is summarised in Table 1.

Table 1. The limiting values of process parameters used for the experimental design.

\begin{tabular}{ccc}
\hline Parameter & Minimum value & Maximum value \\
\hline $\begin{array}{c}\text { Voltage } \\
(\mathrm{kV})\end{array}$ & 10 & 25 \\
$\begin{array}{c}\text { Distance } \\
(\mathrm{cm}) \\
\text { Flow Rate } \\
(\mathrm{ml} / \mathrm{h})\end{array}$ & 10 & 25 \\
\end{tabular}

In the current study a central composite design was employed for the conduction of the experiments. That design is composed by eight factorial, six star and five (or six) centre points. The role of the factorial points is to provide the fundamental data for the curve fitting, the centre points improve the precision of the fitting and the star points facilitate the estimation of curvature. Data coding was performed in order to simplify its processing. The upper limit of the design was given the value $+a$, whereas the lower limit was given the value $-a$. The factorial points had the values +1 and -1 and the star point were set at the point $(0,0,0)$. The experiments were conducted in randomized order, in order to eliminate the probability of systematic error occurance. The coded values of the process parameters used in the experiments and the actual design are shown in Table 2 and Figure 2, respectively.

Table 2. Coded values of the independent values used in the experimental design.

\begin{tabular}{cccc}
\hline Run & $\begin{array}{c}\text { Distance } \\
(\mathrm{cm})\end{array}$ & $\begin{array}{c}\text { Voltage } \\
(\mathrm{kV})\end{array}$ & $\begin{array}{c}\text { Flow Rate } \\
(\mathrm{ml} / \mathrm{h})\end{array}$ \\
\hline 1 & 1 & 1 & -1 \\
2 & 0 & 0 & 0 \\
3 & 1 & -1 & 1 \\
4 & 0 & 0 & 0 \\
5 & -1 & -1 & -1 \\
6 & 0 & 1.68 & 0 \\
7 & 0 & 0 & 0 \\
8 & 0 & 0 & 1.68 \\
9 & 1 & 1 & 1 \\
10 & 0 & 0 & 0 \\
11 & -1 & 1 & -1 \\
12 & 0 & -1.68 & 0 \\
13 & -1 & 1 & 1 \\
14 & 1.68 & 0 & 0 \\
15 & -1.68 & 0 & 0
\end{tabular}




000

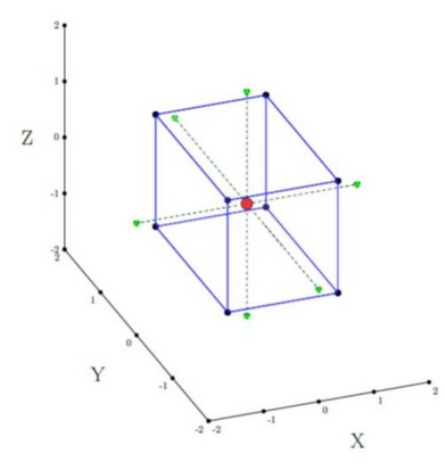

Figure 2. Central composite design. Blue coloured points represent the factorial points, green coloured the star points and the centre point are coloured red.

\subsection{Fibre morphology characterisation}

The produced fibres were sputter coated with gold (Q150T ES, Quorum) and subsequently placed under the microscope (FESEM, Carl Zeiss (Leo) 1530VP). Image analysis (AxioVision software) was used for the measurement of the fibre diameters, pore area and pore perimeter on the fibre surface ${ }^{14}$. Images from at least three different areas of each sample were obtained. The pore size measurements were performed on the surface of, at least, four different fibres from different regions of the sample. The total measured surface area was at least $40 \mu \mathrm{m}^{2}$ for each sample. The surface area of 100-300 individual pores was measured for each sample. Approximately 70 fibres per sample were measured for the calculation of the average diameter. Relative pore covered area (RPCA), calculated by equation (1), was used for the evaluation of the porous surface:

$$
\text { RPCA }=\frac{\text { Sum of pore covered area }}{\text { Total measured fibre surface area }} x 100
$$

The advantage of using RPCA over the average pore diameter or area is that in the first case the accuracy of the method is improved, due to minimization of the pore merging effect. 


\section{Results and discussion}

\subsection{Fibre morphology and size}

Figure 3 shows the SEM images of the fibres produced under different experimental conditions and Table 3 summarises the corresponding experimental conditions and results.
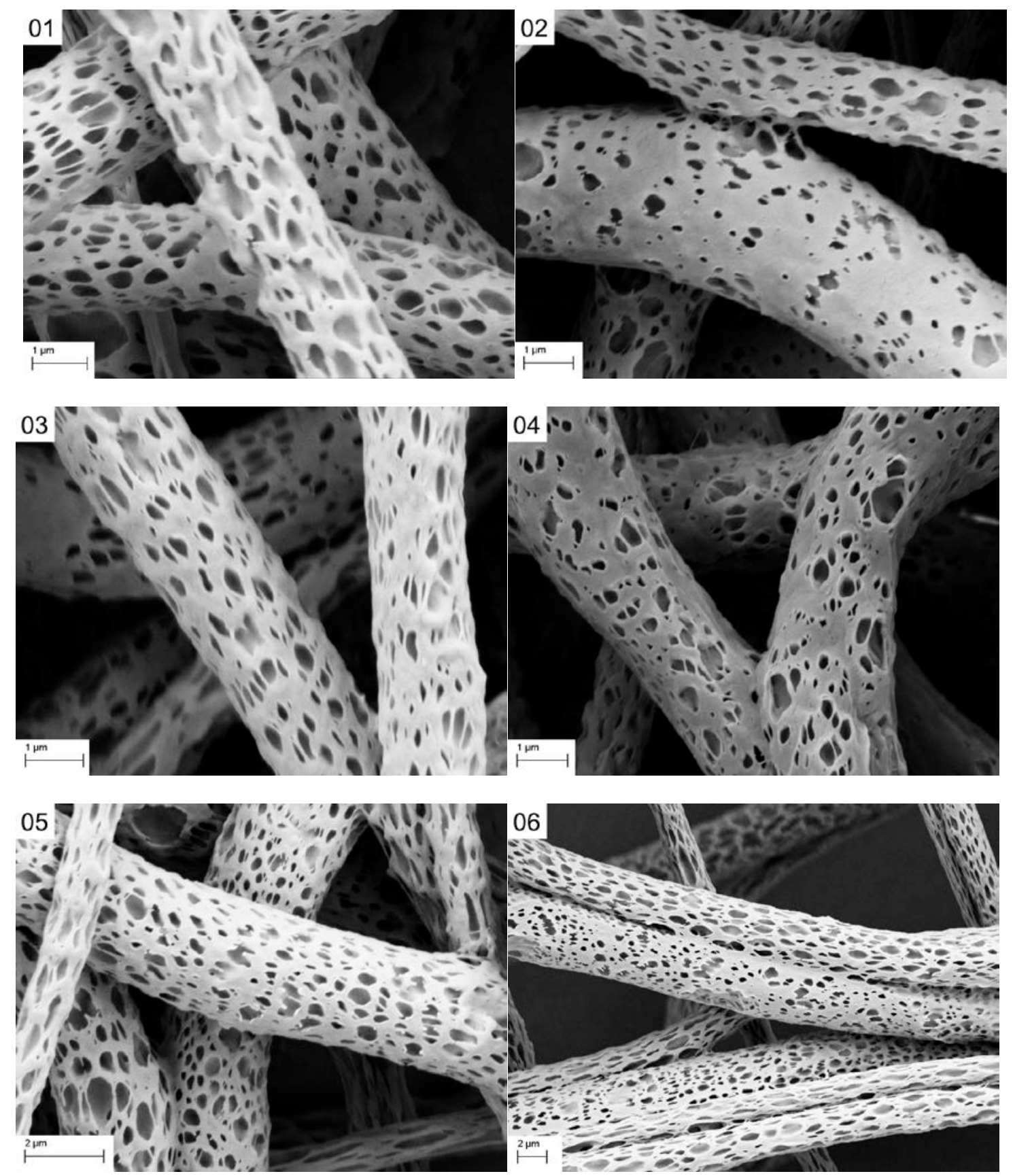

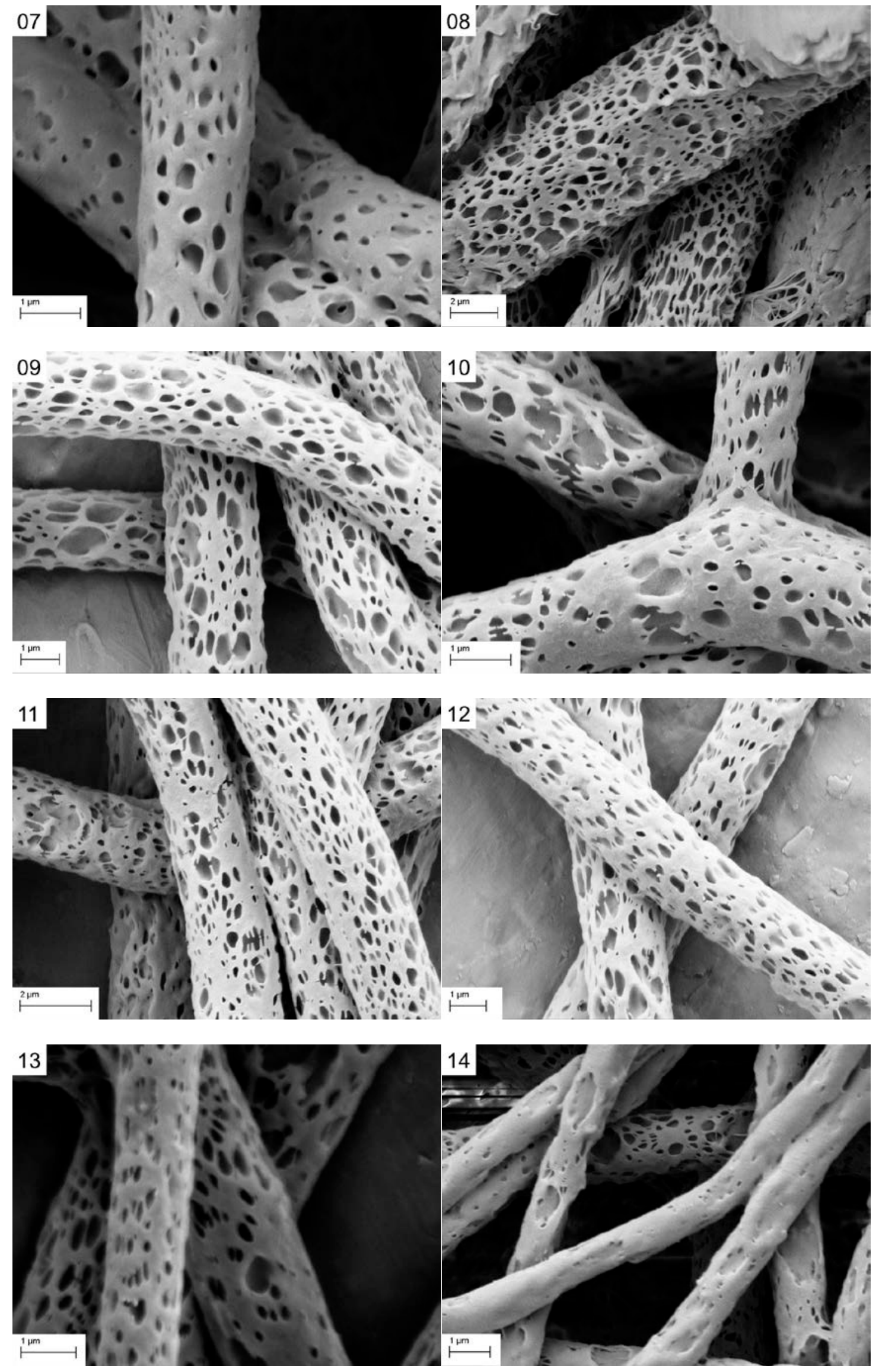

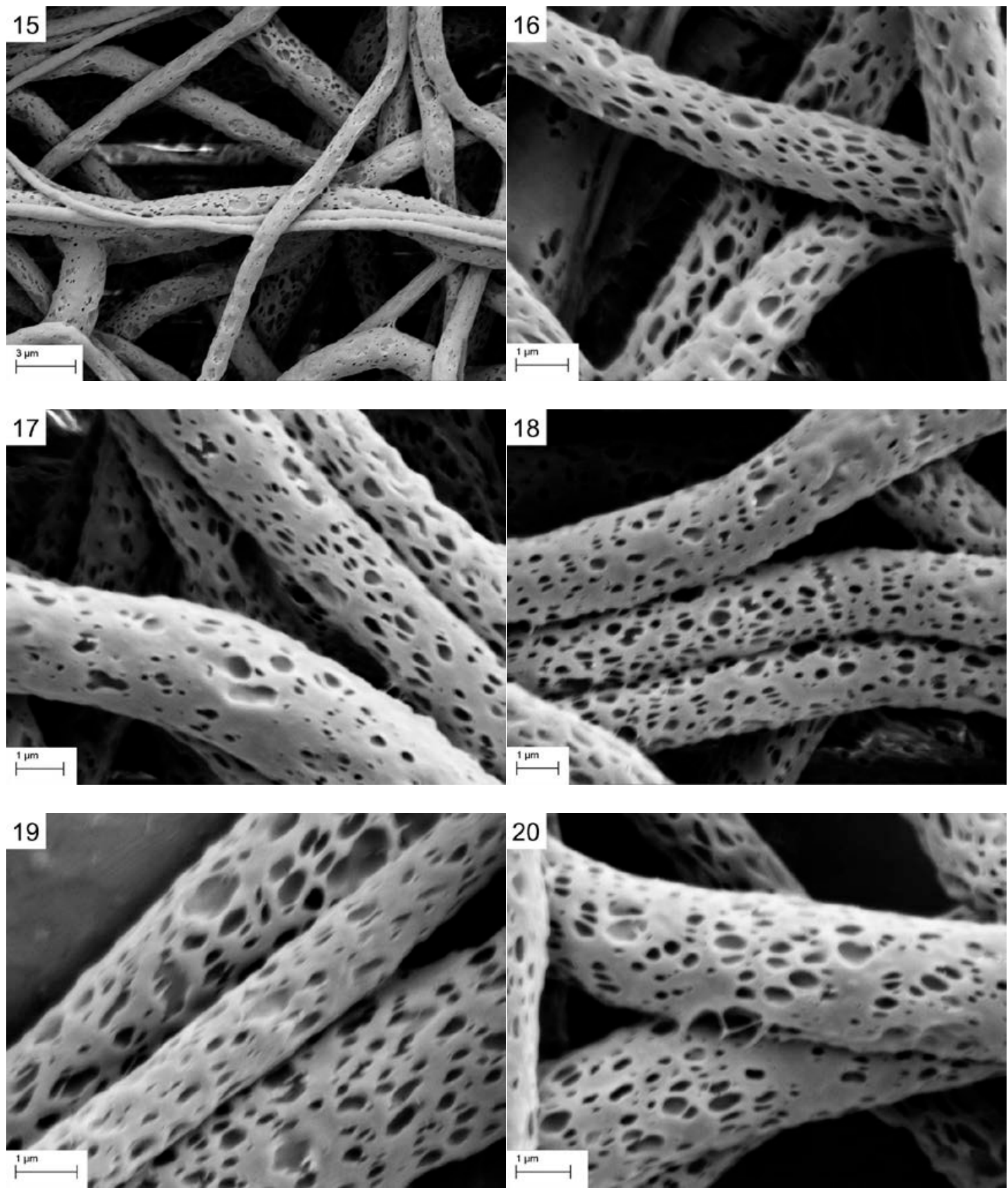

Figure 3. SEM pictures of fibres produced under different experimental conditions. The number at the top left corner represents each experimental run.

Table 3. Uncoded values of controlled and response parameters (* validation runs, NA stands for Not Analysed, NFC stands for No Fibre Collection).

\begin{tabular}{|c|c|c|c|c|c|c|c|c|}
\hline $\begin{array}{c}\mathrm{Ru} \\
\mathrm{n}\end{array}$ & $\begin{array}{c}\text { Distanc } \\
\mathrm{e} \\
(\mathrm{cm})\end{array}$ & $\begin{array}{c}\text { Voltag } \\
\text { e } \\
(\mathrm{kV})\end{array}$ & $\begin{array}{c}\text { Flow } \\
\text { Rate } \\
(\mathrm{ml} / \mathrm{h} \\
\text { ) }\end{array}$ & $\begin{array}{c}\text { Averag } \\
\text { e } \\
\text { diamete } \\
r \\
(\mu \mathrm{m})\end{array}$ & $\begin{array}{c}\text { Average } \\
\text { diameter } \\
\text { coefficien } \\
\text { t of } \\
\text { variation } \\
(\%)\end{array}$ & $\begin{array}{c}\text { Averag } \\
\text { e pore } \\
\text { area } \\
\left(\mu \mathrm{m}^{2}\right)\end{array}$ & $\begin{array}{l}\text { Average } \\
\text { pore area } \\
\text { coefficien } \\
\text { t of } \\
\text { variation } \\
(\%)\end{array}$ & $\begin{array}{c}\text { Relativ } \\
\text { e pore } \\
\text { covere } \\
\text { d area } \\
(\%)\end{array}$ \\
\hline
\end{tabular}




\begin{tabular}{ccccccccc}
\hline 1 & 22 & 22 & 1.41 & 2.32 & 36.7 & 0.102 & 124.3 & 26.5 \\
2 & 17.5 & 17.5 & 2.75 & 2.09 & 23.6 & 0.037 & 159.0 & 18.3 \\
3 & 22 & 13 & 4.09 & 2.01 & 28.5 & 0.036 & 108.5 & 15.8 \\
4 & 17.5 & 17.5 & 2.75 & 2.14 & 21.1 & 0.050 & 87.3 & 17.0 \\
5 & 13 & 13 & 1.41 & 2.19 & 37.0 & 0.080 & 117.4 & 22.7 \\
6 & 17.5 & 25 & 2.75 & 3.31 & 34.6 & 0.299 & 118.1 & 31.9 \\
7 & 17.5 & 17.5 & 2.75 & 2.39 & 24.9 & 0.044 & 106.8 & 18.0 \\
8 & 17.5 & 17.5 & 5 & 2.83 & 45.1 & 0.154 & 95.1 & 28.6 \\
9 & 22 & 22 & 4.09 & 2.49 & 20.2 & 0.062 & 123.9 & 23.9 \\
10 & 17.5 & 17.5 & 2.75 & 2.22 & 17.3 & 0.050 & 128.2 & 17.6 \\
11 & 13 & 22 & 1.41 & 2.52 & 39.6 & 0.053 & 153.1 & 18.3 \\
12 & 17.5 & 10 & 2.75 & 2.42 & 32.2 & 0.059 & 137.4 & 18.1 \\
13 & 13 & 22 & 4.09 & 2.15 & 20.1 & 0.044 & 184.5 & 17.9 \\
14 & 10 & 17.5 & 2.75 & NA & 25.5 & NA & NA & NA \\
15 & 17.5 & 17.5 & 0.5 & NA & 22.5 & NA & NA & NA \\
16 & 22 & 13 & 1.41 & 1.62 & 27.2 & 0.050 & 92.5 & 16.9 \\
17 & 17.5 & 17.5 & 2.75 & 2.04 & 19.5 & 0.048 & 96.9 & 17.2 \\
18 & 13 & 13 & 4.09 & 2.04 & 17.3 & 0.049 & 104.7 & 16.5 \\
$19^{*}$ & 15 & 19 & 2 & 2.62 & 17.4 & 0.052 & 155.8 & 17.0 \\
$20^{*}$ & 20 & 16 & 3.5 & 2.20 & 27.5 & 0.049 & 91.4 & 17.4 \\
21 & 25 & 17.5 & 2.75 & NFC & NFC & NFC & NFC & NFC \\
\hline
\end{tabular}

No fibres were collected when the distance was set at $25 \mathrm{~cm}$ (run 21). The fibres produced at the spinning distance of $10 \mathrm{~cm}$ (run 14) and when the flow rate was 0.5 $\mathrm{ml} / \mathrm{h}$ (run 15) were a mixture of porous and non-porous fibres and, therefore, were excluded from the data analysis. In all the other cases, porous, bead free fibres were produced. As a result of that, the investigated region was reduced to voltages between 10 and $25 \mathrm{kV}$, spinning distances between 13 and $22 \mathrm{~cm}$ and flow rates between 1.41 and $5 \mathrm{ml} / \mathrm{h}$.

The average circularity of the pores for each experimental run was calculated as follows:

$$
f_{\text {por }}=\frac{4 \pi A}{P^{2}}(2)
$$

Where $A$ is the area and $P$ is the perimeter of individual pores. In none of the experimental runs the average circularity of the pores exceeded 0.750 , thus proving the irregular shapes of the pores. The deviation of the average pore circularity from that of a circle $\left(f_{\text {circ }}=1\right.$ ) proves the irregularity of the shapes of the pores and indicates that the main mechanism responsible for the pore formation was phase separation.

\subsection{Models construction and validation}

Multiple linear regression analysis was implemented for the development of the second order polynomial equations correlating the response variables (RPCA and 
fibre average diameter) to the electrospinning process parameters. Least squares method was used for the determination of the coefficients of the equations. The equations are valid within the range of data used for their development (tip-tocollector distance from 13 to $22 \mathrm{~cm}$, applied voltage from 10 to $25 \mathrm{kV}$, feed flow rate from 1.41 to $5 \mathrm{ml} / \mathrm{h}$ ).

$$
\begin{aligned}
& \text { RPCA }=-0.253 \mathrm{x}_{1}^{2}+0.128 \mathrm{x}_{1} \mathrm{x}_{2}+0.060 \mathrm{x}_{1} \mathrm{x}_{3}+6.68 \mathrm{x}_{1}+0.131 \mathrm{x}_{2}^{2}+0.089 \mathrm{x}_{2} \mathrm{x}_{3}-6.46 \mathrm{x}_{2} \\
& +2.60 \mathrm{x}_{3}^{2}-17.9 \mathrm{x}_{3}+34.3(3) \\
& \begin{array}{c}
\mathrm{D}=-0.024 \mathrm{x}_{1}^{2}+0.005 \mathrm{x}_{1} \mathrm{x}_{2}+0.022 \mathrm{x}_{1} \mathrm{x}_{3}+0.685 \mathrm{x}_{1}+0.012 \mathrm{x}_{2}^{2}-0.009 \mathrm{x}_{2} \mathrm{x}_{3}-0.433 \mathrm{x}_{2} \\
+0.128 \mathrm{x}_{3}^{2}-0.930 \mathrm{x}_{3}+0.910(4)
\end{array}
\end{aligned}
$$

Where $x_{1}$ is the tip-to-collector distance, $x_{2}$ is the applied voltage and $x_{3}$ is the feed solution flow rate. The $R^{2}$ values for equations (3) and (4) were 0.93 and 0.96 , respectively, indicating satisfactory data fitting (Figure 4).
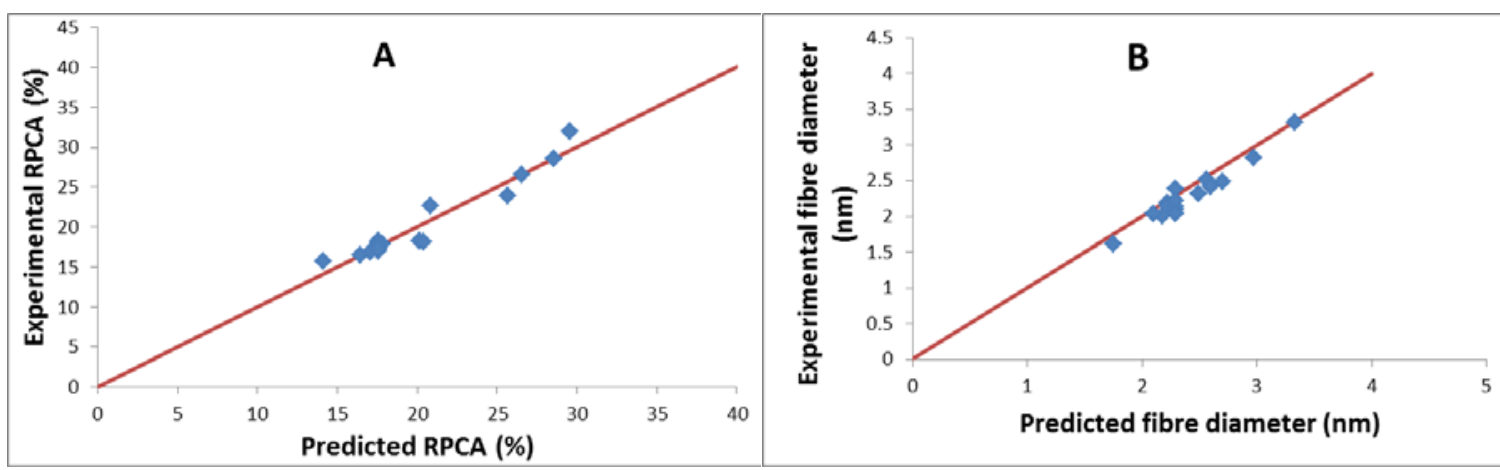

Figure 4. Fitting of the experimental data to the empirical equations ( $A$ ) Relative pore covered area, (B) Average diameter.

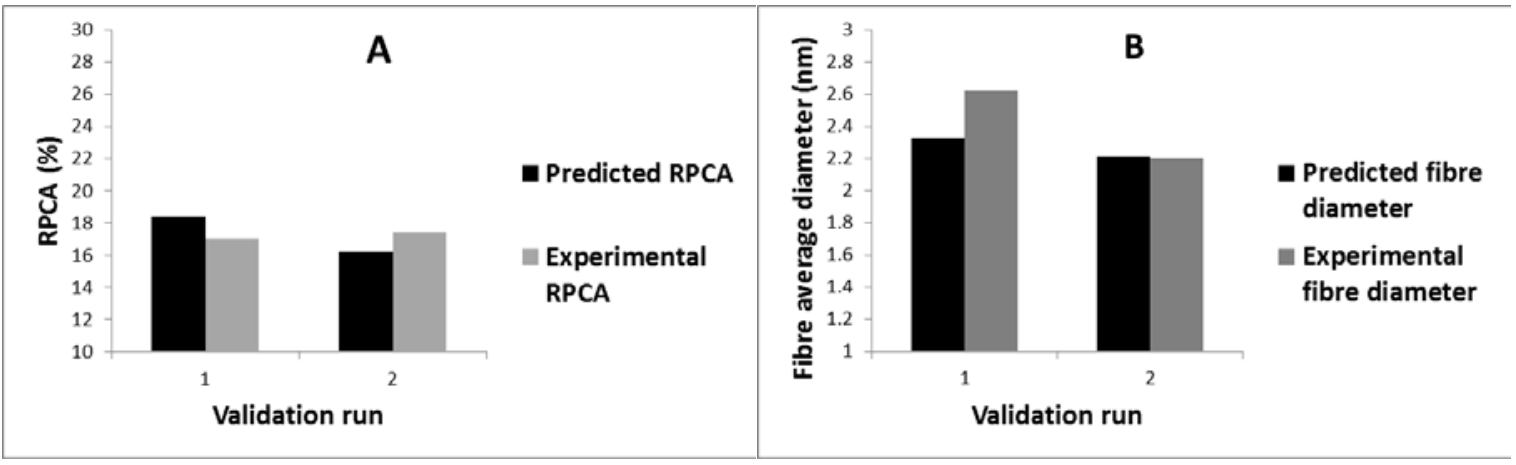

Figure 5. Validation of the empirical equations (A) Relative pore covered area, (B) Average diameter.

Two runs, with randomly selected values of process parameters (Table 3, runs 20 and 21) were used for the validation of equations (3) and (4). Equation (3) predicts relative pore covered areas of 18.4 and $16.3 \%$ for the two validation runs (experimental values 17.0 and $17.4 \%$, respectively) (Figure 5A). Equation (4) predicts average diameters of 2330 and 2210nm (experimental values were 2620 and 2200nm, respectively) (Figure 5B). In all the cases, the differences between the 
predicted and the experimental values are smaller than the standard deviation of the predicted fibre diameters, thus, validating the empirical equations ${ }^{13}$.

\subsection{Electrospinning parameter effect on relative pore covered area}

An overview of the procedure can assist in the better understanding of the electrospinning process parameter effect of the fibre surface morphology. The feed solution is initially at a homogeneous, one phase state. The difference of the solvents' evaporation rates (boiling points of chloroform and DMSO are 61 and 189 ${ }^{\circ} \mathrm{C}$, respectively) causes composition changes within the electrospinning jet after its ejection. The persistently increasing concentration of the less volatile non-solvent (DMSO) becomes the driving force that leads the solution to the crossing of the binodal line and to the two phase region.

Theoretically, longer spinning distances could be expected to result in higher pore covered areas. At longer distances there is more available time for the solution, either to reach the two phase region or to proceed to areas within the two phase region where the pore formation is favoured. The experimental observations confirm that assumption, as seen in Figure 6.
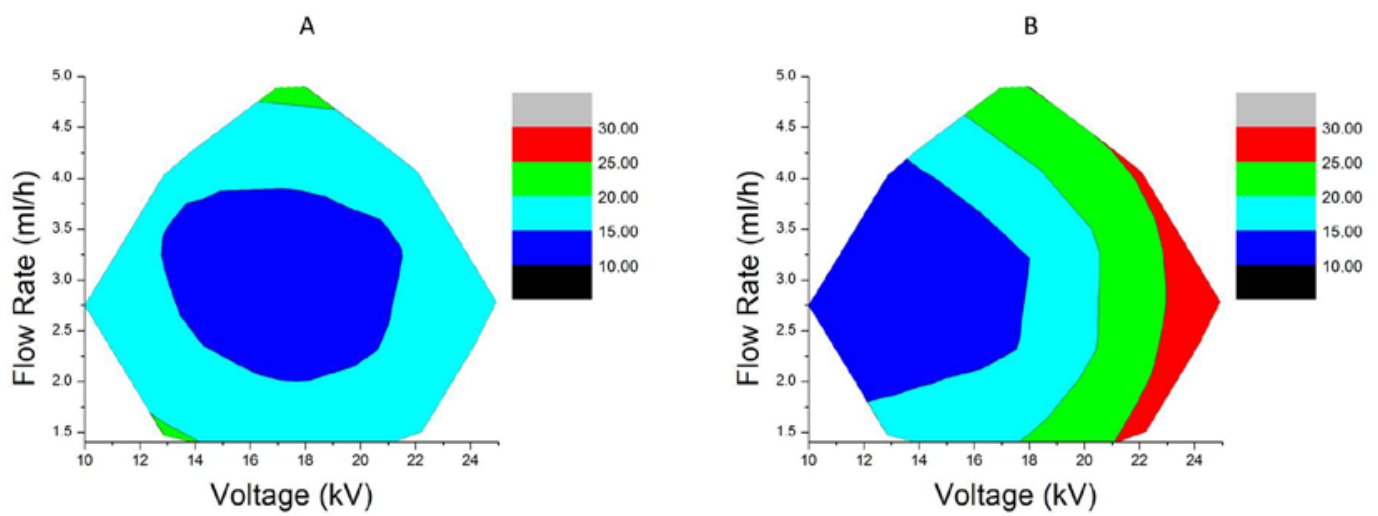

Figure 6. Contour plots of relative pore covered area as a function of flow rate and voltage at (A) Minimum distance, (B) Maximum distance.

At the minimum spinning distance, the range of values of the relative pore covered area lies between $10-20 \%$, whereas, at maximum distance the range is expanded to values up to $30 \%$. This theory is supported by the morphology of the fibres collected at the spinning distance of $10 \mathrm{~cm}$, which were excluded from the equation development. The fibres were a mixture of porous and non-porous fibres due to the lack of time necessary for solution to reach the two phase region. Another interesting observation is that flow rate and voltage seem to have a similar effect at the minimum distance, whereas voltage has a more dominant role at the maximum distance. 
The effect of voltage on the produced fibre morphology is more complex, since several contradicting phenomena are expected to accompany its change. In terms of solution thermodynamics, one might assume that increasing the electrostatic input, the mobility of the charged molecules within the electrospinning jet will subsequently increase. The increased mobility enhances the mixing and hinders the initiation of phase separation. This phenomenon can be compared to the increase of temperature ${ }^{6}$. On the other hand, the increased amount of energy would lead to a subsequent increase of the evaporation rates of the solvents, thus resulting to an earlier induction of the phase separation mechanism and, subsequent elongation of the phase separation window. That enables the ternary system to prolong its presence in the two phase region, where pore formation occurs. Overall, that increases the number of formed pores. In terms of mechanics, the stretching of the jet caused by the voltage during electrospinning can induce phase separation or affect the surface morphology of the produced fibres. Kulichikhin et al. ${ }^{15}$ proved that stretching of entangled polymer solutions can cause phase separation by the formation of a polymer filament surrounded by a liquid shell. In addition to that, the stretching of porous membranes on the uni-axial direction has been proven to increase the pore area at high strains ${ }^{16}$. The effect of stretching is expected to be stronger in electrospun fibres compared to membranes, since the stretching is applied on the fibres before their drying, when they are more vulnerable to external forces. More importantly though, the work by Kim et al. ${ }^{3}$ investigated the deformation of porous fibres under tensile stress. They reported that the fibre undergoes elongation, where the pores are stretched before its deformation by necking. Figure 7 shows the contour plots of relative pore covered area as a function of flow rate and distance at the minimum and maximum values of voltage.
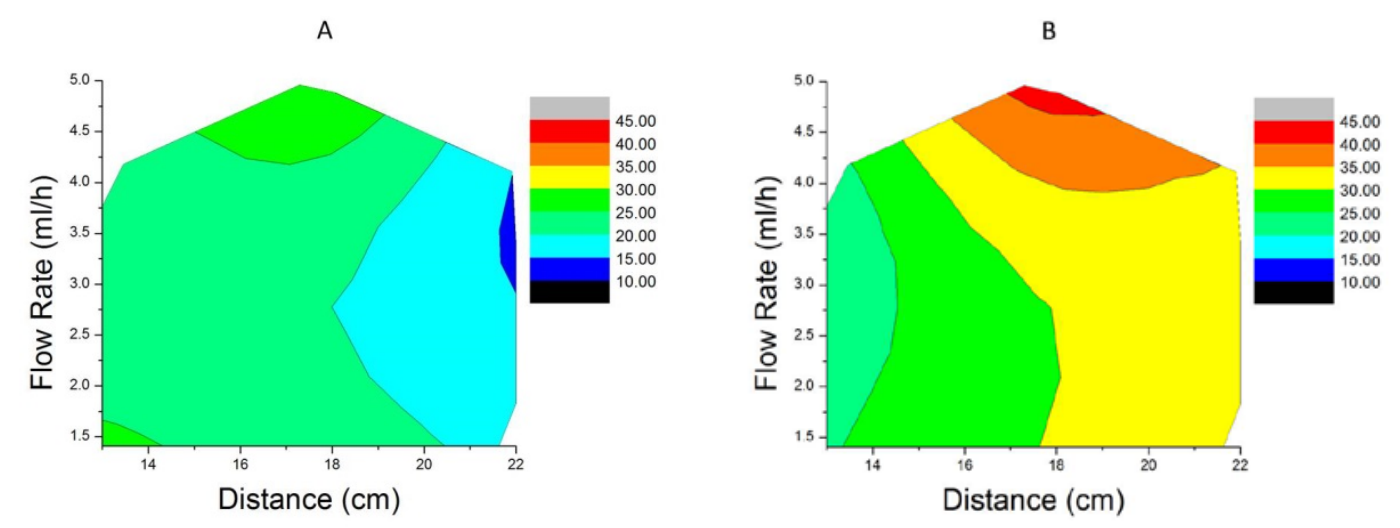

Figure 7. Contour plots of relative pore covered area as a function of flow rate and distance at (A) Minimum voltage, (B) Maximum voltage.

The experimental results prove that the phenomena favouring the increase of RPCA, at elevated voltage values, prevail over their antagonists. The contour plots reveal that an increase of voltage from the minimum to the maximum value results in an increase of the relative pore covered area from $10-30 \%$ to $20-45 \%$. In addition to that, the elliptical shape of the pores, observed at the experiment of maximum voltage 
(Figure 3-06), indicates the importance of the mechanics in the pore size and morphology. The absence of necking suggests that within the investigated limits (voltage up to $25 \mathrm{kV}$ ) increase of voltage is an easy method to increase the RPCA, without any side effects.

Figure 8 shows the contour plots of relative pore covered area as a function of voltage and distance at the minimum and maximum values of flow rate.

A

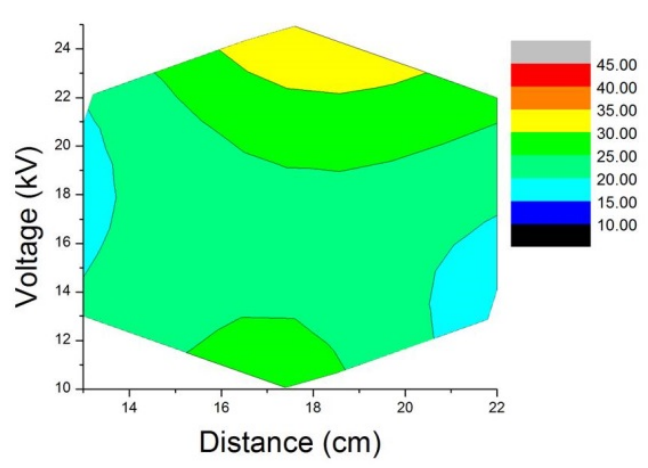

B

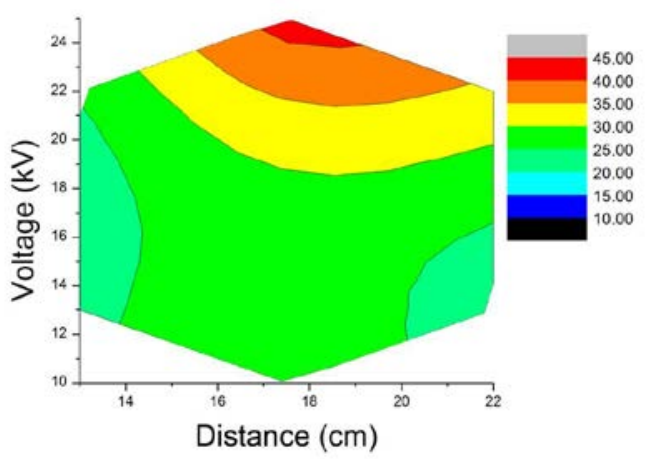

Figure 8. Contour plots of relative pore covered area as a function of voltage and distance at (A) Minimum flow rate, (B) Maximum flow rate.

A comparison between the plots can reveal the effect of flow rate on the fibre surface morphology. High flow rate seems to favour pore formation, since the relative pore covered area lies between $15-35 \%$ for the minimum flow rate value, whereas, the range is shifted to values between $20-45 \%$ when the flow rate is set to its maximum value. The effect is expanded to values outside the investigated region, as indicated by the morphology of the fibres obtained at a flow rate of $0.5 \mathrm{ml} / \mathrm{h}$. The interaction of the spinning distance and voltage is not affected by the value of the flow rate, as indicated by the similar curvature of the contour lines.

A minimum flow rate has to be surpassed for the induction of the thermodynamic instability of the solution. At the minimum flow rate of the experimental design $(0.5$ $\mathrm{ml} / \mathrm{h}$ ), the composition of the electrospinning jet didn't change enough as to initiate the phase separation mechanism (Figure 3-15). Above that lower limit, there is a proportional relationship between the flow rate and the RPCA due to the more intense changes of the composition of the electrospinning jet after its ejection. In addition to that, de Moel et al. ${ }^{17}$ proved that high flow rates for linear polymer solutions can shift the critical temperature and favour demixing of the solution. High flow rates favour different polymer chain configurations in the polymer poor and polymer rich phases. Macromolecular chains in the polymer poor phase can be subjected to stretching easier compared to those in the polymer rich phase, which leads to an increase of polymer solvent contacts and, therefore, to a difference in the polymer solvent interaction energy between the two phases. 
A new method was implemented for the quantification of individual parameter effect. Values of the relative pore covered area were calculated for three cases for each individual parameter (when the other two variables were set at their minimum, medium and maximum values, respectively). In each series, the difference between the maximum and minimum value of the response (relative pore covered area) provided an indication of its dependence on the individual parameter. The parameters can be subsequently classified based on their individual responses' value difference. The investigated region is not symmetrical, therefore new coding of the independent variables was necessary, in order to achieve uniform comparison. Equation (5) assisted the determination of eleven equivalent values for each individual parameter, for which the relative pore covered area was calculated.

$$
\mathrm{x}_{\mathrm{i}}=\mathrm{x}_{\min }+i\left(\frac{\mathrm{x}_{\max }-\mathrm{x}_{\min }}{10}\right), i=0,1,2, \ldots, 10(5)
$$

Where $x_{\min }$ and $x_{\max }$ are the minimum and maximum values of any individual parameter within the analysed region, respectively. The results are shown in Figure 9.
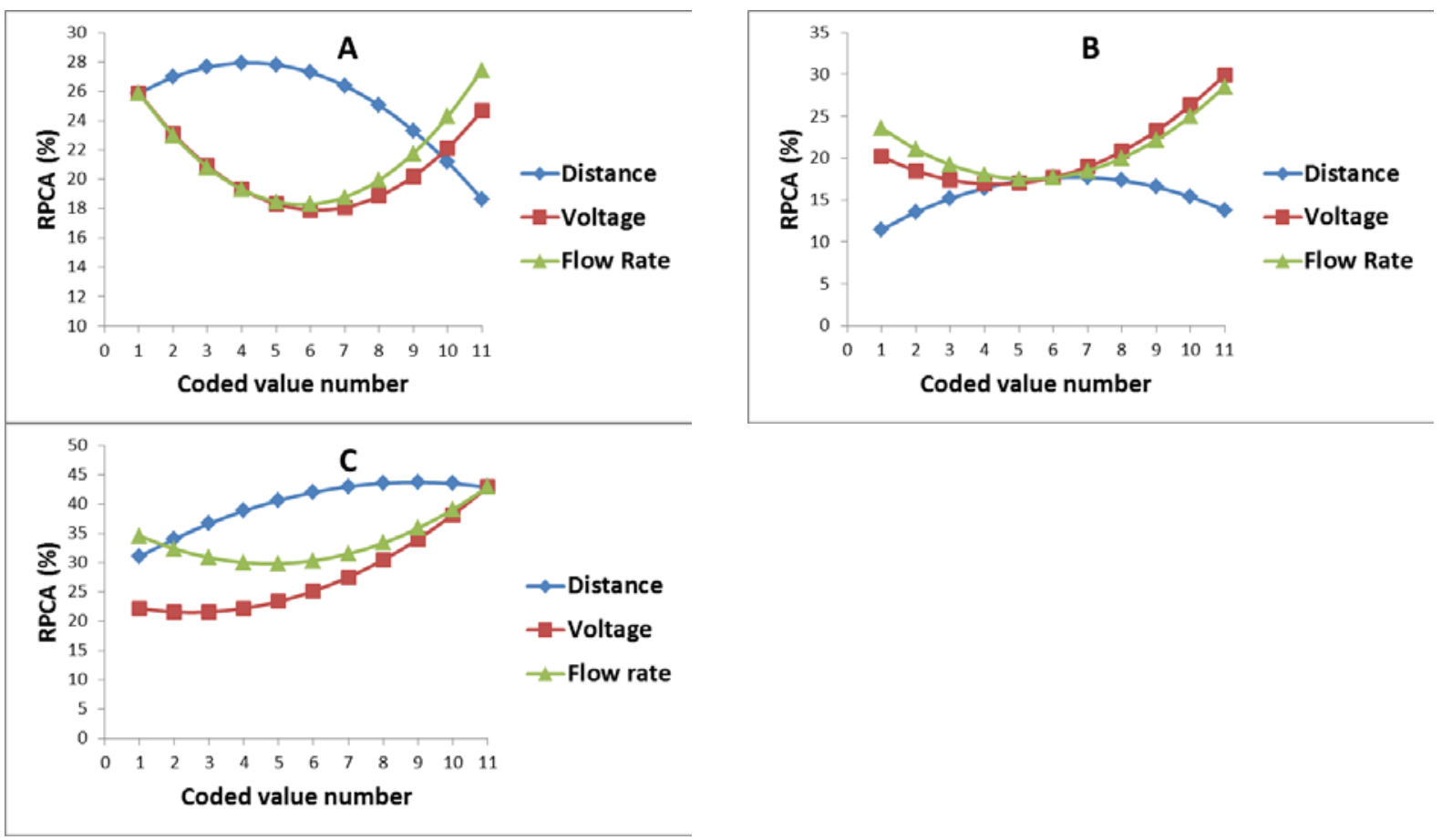

Figure 9. Relative pore covered area as a function of individual parameters at (A) minimum values, $(B)$ medium values, $(C)$ maximum values.

In the cases were the variables were set, either at their minimum, or at their medium values, all the parameters had comparable effect on the pore formation. However, when the values are set at their maximum values, voltage seems to have a stronger effect on the relative pore covered area. Variations of voltage result a change of $21.3 \%$ of relative pore covered area, instead of $13.0 \%$ for flow rate and $12.7 \%$ for distance. 
The local extrema of equation (3) were calculated. If a maximum or minimum exists, it will be located at the point where the partial derivatives of equation (3) are equal to zero, as defined by the system (6).

$$
\frac{\partial \mathrm{RPCA}}{\partial \mathrm{x}_{1}}=0, \frac{\partial \mathrm{RPCA}}{\partial \mathrm{x}_{2}}=0, \frac{\partial \mathrm{RPCA}}{\partial \mathrm{x}_{3}}=0 \text { (6) }
$$

The solution of system (6) predicted a stationary point at $\left(x_{1}, x_{2}, x_{3}=17.4,15.1\right.$, 2.98), which is within the investigated region. The characterization of the stationary point as a maximum, minimum or saddle point occurred by the sign of the determinants of the determinants, shown in equations (7), (8) and (9).

$$
\begin{gathered}
\left|\mathrm{H}_{1}\right|=\frac{\partial \mathrm{RPCA}}{\partial \mathrm{x}_{1} \partial \mathrm{x}_{1}}<0 \text { (7) } \\
\left|\mathrm{H}_{2}\right|=\left|\begin{array}{ll}
\frac{\partial \mathrm{RPCA}}{\partial \mathrm{x}_{1} \partial \mathrm{x}_{1}} & \frac{\partial \mathrm{RPCA}}{\partial \mathrm{x}_{1} \partial \mathrm{x}_{2}} \\
\frac{\partial \mathrm{RPCA}}{\partial \mathrm{x}_{2} \partial \mathrm{x}_{1}} & \frac{\partial \mathrm{RPCA}}{\partial \mathrm{x}_{2} \partial \mathrm{x}_{2}}
\end{array}\right|<0(8) \\
\left|\mathrm{H}_{3}\right|=\left|\begin{array}{lll}
\frac{\partial \mathrm{RPCA}}{\partial \mathrm{x}_{1} \partial \mathrm{x}_{1}} & \frac{\partial \mathrm{RPCA}}{\partial \mathrm{x}_{1} \partial \mathrm{x}_{2}} & \frac{\partial \mathrm{RPCA}}{\partial \mathrm{x}_{1} \partial \mathrm{x}_{3}} \\
\frac{\partial \mathrm{RPCA}}{\partial \mathrm{x}_{2} \partial \mathrm{x}_{1}} & \frac{\partial \mathrm{RPCA}}{\partial \mathrm{x}_{2} \partial \mathrm{x}_{2}} & \frac{\partial \mathrm{RPCA}}{\partial \mathrm{x}_{2} \partial \mathrm{x}_{3}} \\
\frac{\partial \mathrm{RPCA}}{\partial \mathrm{x}_{3} \partial \mathrm{x}_{1}} & \frac{\partial \mathrm{RPCA}}{\partial \mathrm{x}_{3} \partial \mathrm{x}_{2}} & \frac{\partial \mathrm{RPCA}}{\partial \mathrm{x}_{3} \partial \mathrm{x}_{3}}
\end{array}\right|>0(9)
\end{gathered}
$$

The signs determine that the stationary point is a saddle point.

\subsection{Electrospinning parameter effect on fibre average diameter}

Generally, there should be noted that a universal effect of individual electrospinning process parameter on fibre average diameter does not exist. Individual parameters might have different effect on the produced fibre average diameter, depending on other variables, such as the polymer/solvent system or, even, the MW of the polymer ${ }^{18}$. Usually, an increase of the applied voltage results in fibre diameter reduction due to the increased stretching of the electrospinning jet ${ }^{19}$, even though, cases, where voltage seems to have the reverse effect ${ }^{19}$, have also been reported. Solution flow rate affects the produced fibre average diameter in terms of solvent evaporation rates. In most cases, an increase in fibre diameter occurs as a result of an increased flow rate ${ }^{18}$. Nevertheless, flow rate might as well not have any effect on fibre diameters, as Sencadas et al. ${ }^{21}$ reported for electrospinning of chitosan in TFA/DCM solution. In that case, the volatility of the solvents facilitated the complete solvent evaporation during the flight of the jet. Large distances, theoretically, favour the formation of fibres with smaller diameters since that elongates the time of the jet 
stretching, yet there have been reports showing no correlation between distance and fibre diamete ${ }^{20}$. One must take into consideration that in this current study, besides electrospinning parameters, the phase separation effect also contributes to the observed fibre size, through pore formation.

Figure 10 shows the contour plots of average fibre diameter as a function of voltage and distance at the minimum and maximum values of flow rate. A comparison between the plots can reveal the effect of flow rate on the fibre average diameter.
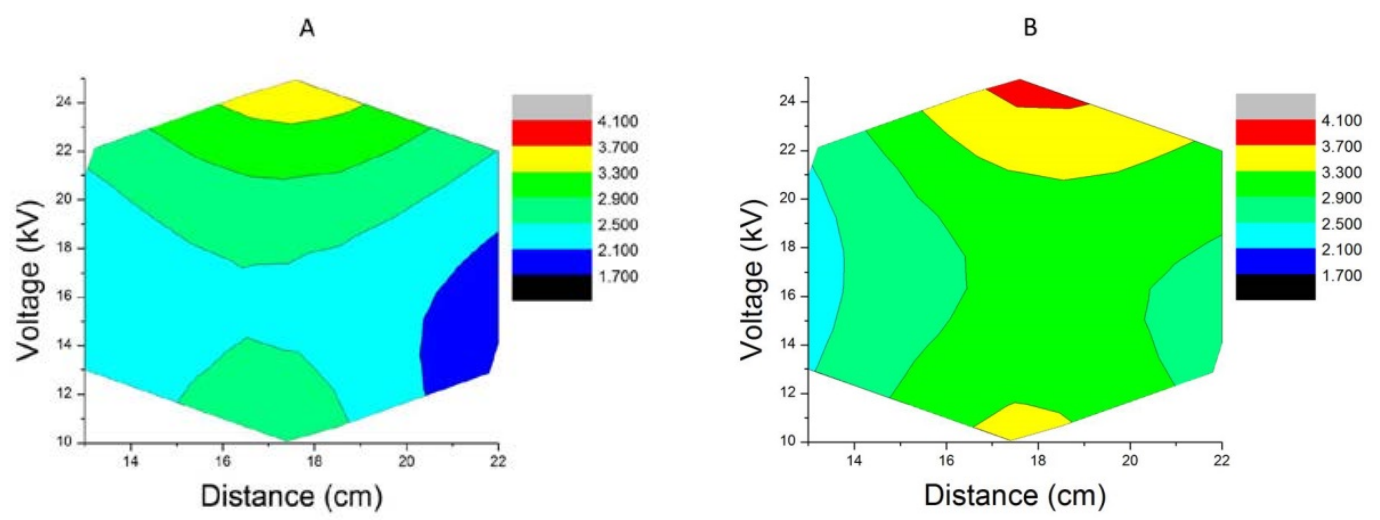

Figure 10. Contour plots of fibre average diameter as a function of voltage and distance at (A) Minimum flow rate, (B) Maximum flow rate.

The equation predicts an increase in the average diameter of the produced fibres as a result of an increase in the flow rate. The majority of the produced fibre average diameter lies within the experimental region lies between the range of $2100-2900 \mathrm{~nm}$ for minimum flow rate, whereas, that increases to values above $2900 \mathrm{~nm}$ for maximum flow rate. The larger amount of solution, which is ejected at high flow rates, cannot be sufficiently stretched, therefore, the diameter of the produced fibres is relatively high.

Figure 11 shows the contour plots of average fibre diameter as a function of voltage and flow rate at the minimum and maximum values of distance. A comparison between the plots can reveal the effect of spinning distance on the fibre average diameter.
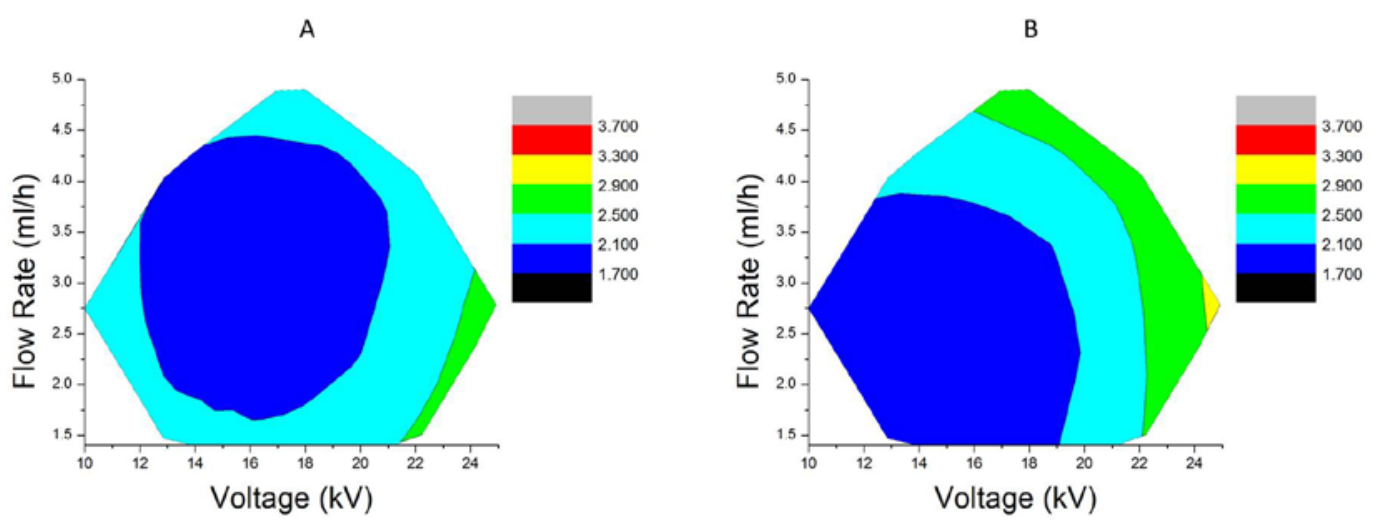
Figure 11. Contour plots of fibre average diameter as a function of flow rate and voltage at (A) Minimum distance, (B) Maximum distance.

Interestingly, the equation predicts a slight increase of the fibre diameter with the increase of distance. At the minimum spinning distance the majority of the produced fibre average diameter lies between $1700-2300 \mathrm{~nm}$, and reaches up to $2900 \mathrm{~nm}$, whereas, at the maximum distance the region where fibres with diameters above $2700 \mathrm{~nm}$ is increased and the fibres with diameters up to $3100 \mathrm{~nm}$ can be produced. Even though that seems to contradict the theory, one must bear in mind that longer spinning distances favour pore formation. The void generated by the pores contributes to the total measured fibre diameter, hence, the proportional relationship between spinning distance and fibre diameter is observed.

Figure 12 shows the contour plots of average fibre diameter as a function of flow rate and distance at the minimum and maximum values of voltage. A comparison between the plots can reveal the effect of voltage on the fibre average diameter.
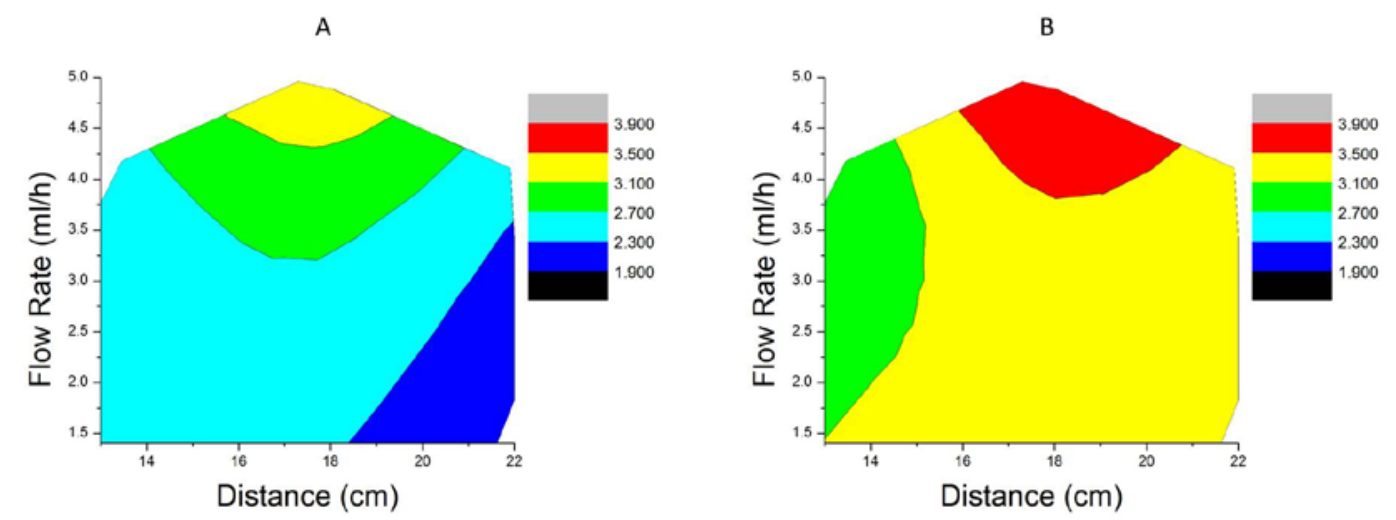

Figure 12. Contour plots of fibre average diameter as a function of flow rate and distance at (A) Minimum voltage, (B) Maximum voltage.

Voltage increases seem to favour the production of fibres with larger diameters. The range of fibre diameters for the minimum voltage is between $1900-3500 \mathrm{~nm}$, whereas it is shifted to values between 2700-3900 for the maximum voltage. Similarly to the distance effect, the observed increase of the fibre diameter increase can be attributed to the increased tendency for pore formation accompanying the increase of voltage.

Coded values from equation (5) were used to compare the effect of the individual parameters on the fibre diameter (Figure 13). 

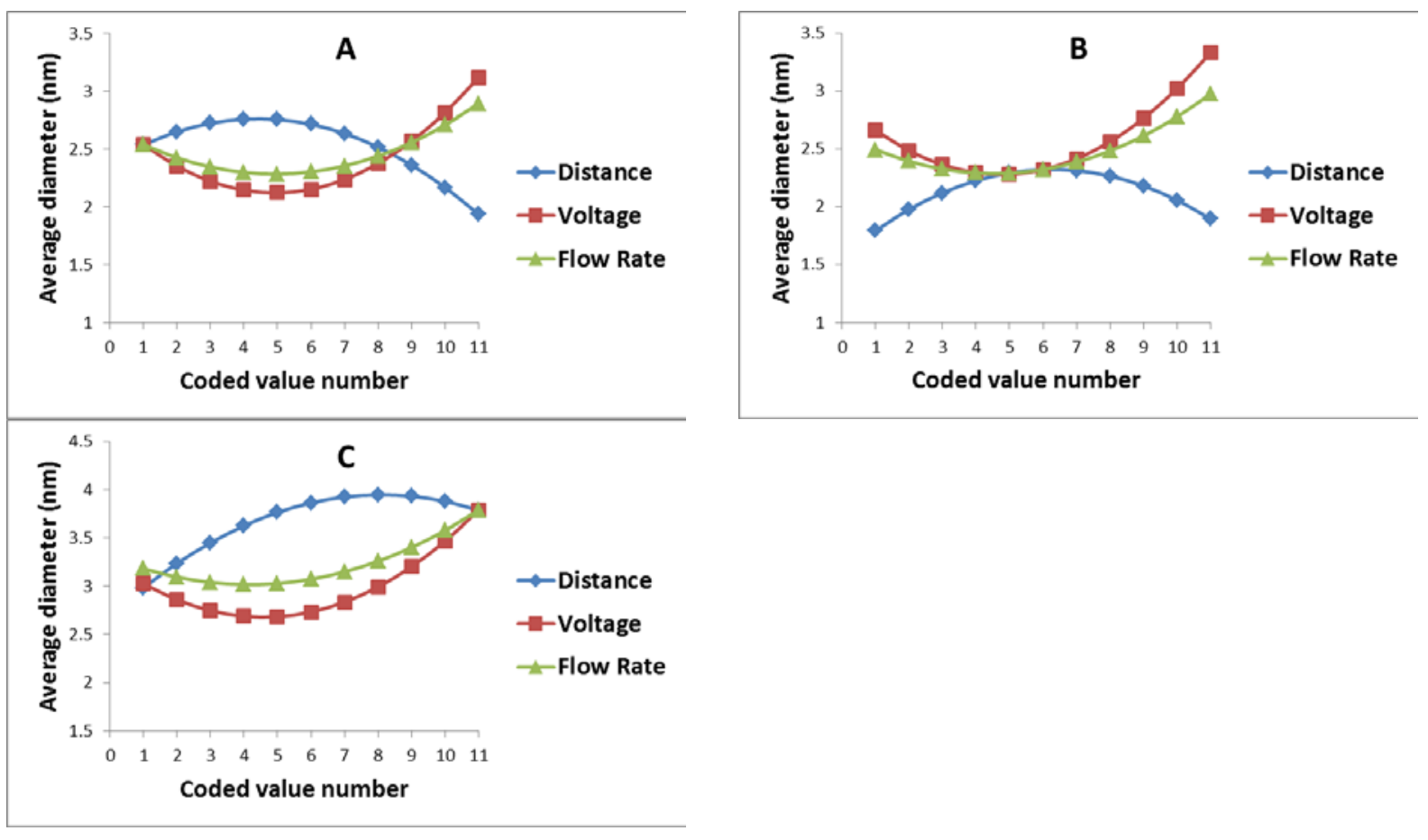

Figure 13. Fibre average diameter as a function of individual parameters at $(A)$ minimum values, (B) medium values, (C) maximum values.

Voltage remains the most influential parameter, however, the average diameter seems to be more responsive at the medium range of values (diameter differences of $1050 \mathrm{~nm}$, compared to $530 \mathrm{~nm}$ for distance and $680 \mathrm{~nm}$ for flow rate).

The local extrema of equation (5) were calculated, following a similar methodology to that of the RPCA. The solution of the system, where the first derivatives of equation (5) were equal to zero, predicted a stationary point at $\left(x_{1}, x_{2}, x_{3}=17.1,15.5,2.71\right)$. The determinants were all negative, therefore the stationary point was characterised as saddle point.

\section{Conclusions}

The effect of individual electrospinning process parameter (applied voltage, spinning distance, and solution flow rate) on electrospun PCL fibre morphology and size, in a combined electrospinning and phase separation process, was investigated in this study. Electrospinning experiments, conducted at conditions determined by a central composite design, generated the necessary data for the development of second order polynomial equations correlating the relative pore covered area and the fibre average diameter to electrospinning process parameters. The empirical models predict an increase of both, relative pore covered area and fibre average diameter, with the increase of any of the electrospinning process parameters. Voltage seems to have the strongest impact on the produced fibre morphology and size. 


\section{References}

1. Hu, Y.; Winn, S.R.; Krajbich, I.; Hollinger, J.O. Porous Polymer Scaffolds Surface-modified with Arginine-glycine-aspartic Acid Enhance Bone Cell Attachment and Differentiation in Vitro J. Biomed. Mater. Res. A 2003, 64A (3), 583-590.

2. Moroni, L.; Licht, R.; Boer, J.; Wijn, J.R.; Blitterswijk, C.A. Fiber Diameter and Texture of Electrospun Peot/pbt Scaffolds Influence Human Mesenchymal Stem Cell Proliferation and Morphology, and the Release of Incorporated Compounds Biomaterials, 2006, 27, 4911-4922.

3. Kim, G.M.; Lach, R.; Michler, G.H.; Chang, Y.-W. The Mechanical Deformation Process of Electrospun Polymer Nanocomposite Fibers Macromol. Rapid Comm., 2005, 26, 728-733.

4. Srinivasarao, M.; Collings D.; Philips A.; Patel S. Three-Dimensionally Ordered Array of Air Bubbles in a Polymer Film Science, 2001, 292, 79 - 83.

5. Bayley, G.M.; Mallon P.E. Porous Microfibers by the Electrospinning of Amphiphilic Graft Copolymer Solutions with Multi-walled Carbon Nanotubes Polymer 2012, 53, 5523-5539.

6. Fashandi, H.; Karimi, M. Pore Formation in Polystyrene Fiber by Superimposing Temperature and Relative Humidity of Electrospinning Atmosphere Polymer 2012, 53, 5832-5849.

7. Nezarati, R.M.; Eifert, M.B.; Cosgriff-Hernandez, E. Effects of Humidity and Solution Viscosity on Electrospun Fiber Morphology Tissue Eng. Part C 2013, 19, 1-10. 
8. Qi, Z.; Yu, H.; Chen, Y.; Zhu, M. Highly Porous Fibers Prepared by Electrospinning a Ternary System of Nonsolvent/solvent/poly(L-lactic Acid) Mater. Lett. 2009, 63, 415-418.

9. Megelski, S.; Stephens, J.S.; Chase, D.B.; Rabolt, J.F. Micro- and Nanostructured Surface Morphology on Electrospun Polymer Fibers Macromolecules 2002, 35, 8456-8466.

10. Touny, A.H.; Bhaduri S.B. A Reactive Electrospinning Approach for Nanoporous Pla/monetite Nanocomposite Fibers Mat. Sci. Eng. C 2010, 30, 1304-1312.

11. Katsogiannis, K.A.G.; Vladisavljević, G.T.; Georgiadou, S. Production of Porous Electrospun PCL Fibres by Phase Separation Eur. Pol. J., 2015, 69, 284-295.

12.Kong, L.; Ziegler, G.R. Quantitative Relationship Between Electrospinning Parameters and Starch Fiber Diameter Carbohydr. Polym. 2013, 92, 1416- 1422. 13. Sukigara, S.; Gandhi, M.; Ayutsede, J.; Micklus, M.; Ko, F. Regeneration of Bombyx Mori Silk by Electrospinning. Part 2. Process Optimization and Empirical Modeling Using Response Surface Methodology Polymer 2004, 45, 3701-3708.

14. Casper, C.L.; Stephens, J.S.; Tassi, N.; Chase, D.B.; Rabolt J.F. Controlling Surface Morphology of Electrospun Polystyrene Fibers: Effect of Humidity and Molecular Weight in the Electrospinning Process Macromolecules 2004, 37, 573578.

15. Kulichikhin, V.G.; Malkin, A.Y.; Semakov, A.V.; Skvortsov, I.Y.; Arinstein A. Liquid Filament Instability Due to Stretch-induced Phase Separation in Polymer Solutions Eur. Phys. J. E 2014, 37, 10-16.

16. Morehouse, J.A.; Worrel, L.S.; Taylor, D.; Lloyd, D.R.; Freeman, B.D.; Lawler, D.F. The Effect of Uni-axial Orientation on Macroporous Membrane Structure J. Porous Mater. 2006, 13, 61-72. 
17.De Moel, K.; Flikkema, E.; Szleifer, I.; ten Brinke, G. Europhys. Lett., Flowinduced Phase Separation in Polymer Solutions 1998, 42, 407-412.

18. Ojha, S.S.; Afshari, M.; Kotek, R.; Gorga R.E. Morphology of Electrospun Nylon-6 Nanofibers as a Function of Molecular Weight and Processing Parameters J. Appl. Pol. Sci. 2008, 108, 308-319.

19.Geng, X.; Kwon, O.-H.; Jang, J. Electrospinning of Chitosan Dissolved in Concentrated Acetic Acid Solution Biomaterials 2005, 26, 5427-5432.

20.Zhang, C.; Yuan, X.; Wu, L.; Han, Y.; Sheng, J. Study on Morphology of Electrospun Poly(Vinyl Alcohol) Mats Eur. Pol. J. 2005, 41, 423-432.

21. Sencadas, V.; Correia, D.M.; Areias, A.; Botelho, G.; Fonseca, A.M.; Neves, I.C.; Gomez Ribelles, J.L.; Lanceros Mendez, S. Determination of the Parameters Affecting Electrospun Chitosan Fiber Size Distribution and Morphology Carbohydr. Polym. 2012, 87, 1295-1301. 